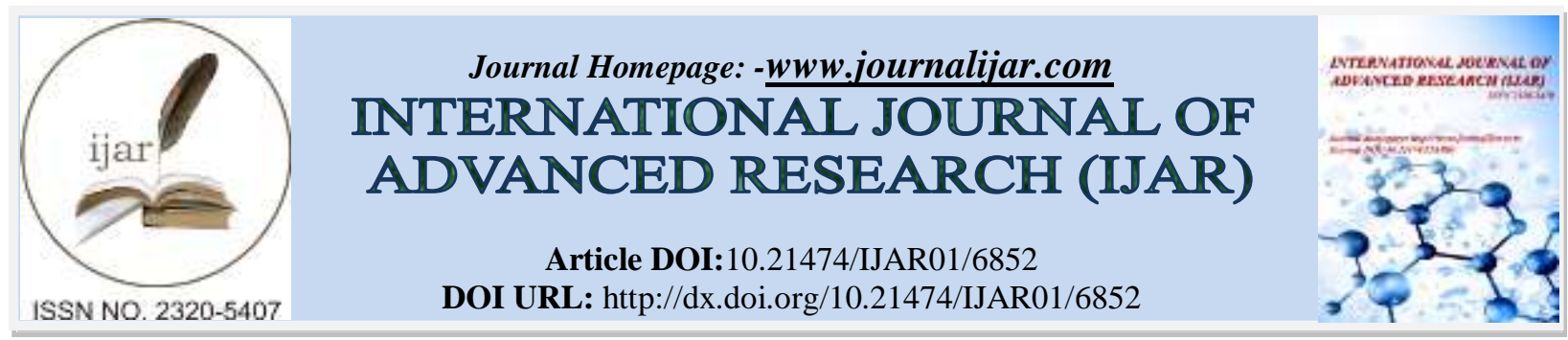

RESEARCH ARTICLE

\title{
ANTI-CORROSIVE PROPERTIES OF SILICA NANOPARTICLES AND RARE EARTH SEALING ON ANODIZED ALUMINUM.
}

\author{
W. A. Hussein. \\ Chemistry Department, Faculty of Science (Girls), Al-Azhar University, Nasr City, Cairo, Egypt.
}

\section{Manuscript Info}

Manuscript History

Received: 05 February 2018

Final Accepted: 07 March 2018

Published: April 2018

Keywords:-

Aluminum alloy, Anodizing, Conversion

coating, Sealing, Nano-particles.

\section{Abstract}

The present study is aimed at investigating the electrochemical characteristics of aluminum alloy due to the deposition of $\mathrm{SiO}_{2}$ nanoparticles by electrophoretic deposition (EPD) inside a porous anodic aluminum oxide film (AAO) followed by sealing using cerium conversion coating technique. Treated aluminum exhibits improved surface morphology and higher corrosion resistance when subjected to $3.5 \% \mathrm{NaCl}$ as evidenced by lower corrosion current density and higher polarization resistance.

Copy Right, IJAR, 2018,. All rights reserved.

\section{Introduction:-}

Pure aluminum and aluminum alloys are extensively used by the industry for various applications. However the major disadvantage is that the materials undergo degradation very easily. Different types of surface treatments, such as anodizing, are used to improve corrosion resistance [1-11]. An aluminum oxide produced in the anodizing process consists of two layers, i.e. a very thin nonporous barrier type layer located close to the surface and a porous layer with a much larger thickness. In order to improve the corrosion resistance of aluminum alloys, the oxide produced on the surface is used for further treatment leading to sealing of existing pores [10]. Sealing treatment is physical or chemical process for the porous layer of anodic films in order to reduce the porosity and adsorption capacity of oxide layers and improve corrosion resistance of aluminum alloy [11]. So far, according to the previous researches [12-18], numerous sealing methods were developed and applied, different sealing techniques had the limited conditions and exhibited different influences on corrosion resistance. Seo et al. [19] reported that pores can be partially filled by nanoparticles using the dip-coating process. But, with this method, only a slight amount of nanoparticles were deposited at the bottom of pores. As a result the quantity of nanoparticles into pores is too low to fill them completely. Because the migration of charged particles toward the pore bottom is promoted by applying an electric field, the electrophoretic deposition (EPD) technique should increase the density of particles in comparison with the dip-coating process. EPD of silica is an easy process because silica suspensions are characterized by spherical particles and a high negative zeta potential, providing good stability of the suspension and efficient migration $[20,21]$. However, bubble generation coming from water hydrolysis during EPD interrupted the deposition and causes some of the nanometer order partials fail to deposit [22].

The main scope of this work is to evaluate synergistic effect of impregnation of the porous layer by nano-sized silicon dioxide particles via EPD process followed by using cerium conversion coating to seal the pores of anodic aluminum oxide film (AAO). The corrosion resistance of the resulting anodized coating has been determined during exposure to $3.5 \% \mathrm{NaCl}$ using different electrochemical techniques.

Corresponding Author:- W. A. Hussein.

Address:- Chemistry Department, Faculty of Science (Girls), Al-Azhar University, Nasr City, 


\section{Experimental:-}

Material:-

The material used was 1050A aluminum alloy. The chemical composition in weight percent is listed in Table 1 .

\section{Preparation of the anodic film:-}

Before anodizing, the alloy sheet was degreased with ethanol then etched in $\mathrm{NaOH}\left(0.5 \mathrm{~g} \mathrm{~L}^{-1}\right)$ aqueous solution at $40{ }^{\circ} \mathrm{C}$ for $5 \mathrm{~min}$ and finally neutralized in $\mathrm{HNO}_{3}(25 \mathrm{vol} \%)$ at room temperature for $2 \mathrm{~min}$. To facilitate the insertion of particles inside pores, the porosity of the anodic films has to exhibit low tortuosity and pore diameter larger than the silica particle one $(\sim 20 \mathrm{~nm})$. Since large pores (average pore diameter $>100 \mathrm{~nm}$ ) are required, the aluminum sheet was anodized galvanostatically $\left(1.5 \mathrm{Adm}^{-2}\right)$ in a temperature controlled phosphoric acid bath $\left(0.4 \mathrm{~mol} \mathrm{~L}^{-1}\right)$ for 20 min where $\mathrm{Pb}$ sheet served as a cathode [23]. After anodizing, the specimens were rinsed fully in distilled water for subsequent use.

\section{Sealing process:-}

The first step in sealing process was the impregnation of $\mathrm{SiO}_{2}$ nanoparticles using electrophoretic deposition (EPD) technique. In which, anodized samples were set as the cathode and the lead foil as the anode. Particles deposition bath media was prepared by diluting $\mathrm{SiO}_{2}$ colloidal samples with ultra pure water to be $2 \mathrm{wt} \%$. The $\mathrm{pH}$-value adjusted oneself on $\mathrm{pH}=10$. The substrate was dried at ambient temperature for subsequent use. The second sealing step was the immersion of impregnated samples in a solution containing $\mathrm{Ce}\left(\mathrm{NO}_{3}\right)_{3}$, then rinsed with distilled water and dried with air. The parameters of the rare earth sealing process are described in Table 2. Surface morphology of anodic oxide films after different sealing steps was examined by JEOL JSM54 10 (Japan) computer controlled Scanning Electron Microscope (SEM).

\section{Electrochemical test:-}

Electrochemical measurements were performed using Voltalab 40 Potentiostat PGZ301 (Germany) and Volta Master 4 software for measuring and analyzing the corrosion rate. As received aluminum alloy, anodized aluminum oxide (AAO), AAO impregnated with $\mathrm{SiO}_{2}$ nanoparticles and AAO sealed with both $\mathrm{SiO}_{2}$ nanoparticles and $\mathrm{Ce}\left(\mathrm{NO}_{3}\right)_{3}$ served as the working electrodes. A saturated calomel electrode (SCE) and a platinum disc were used as the reference and counter electrode, respectively. All the electrochemical tests were carried out in $3.5 \% \mathrm{NaCl}$ solution (Sigma Aldrich). At first the open circuit potential (ocp) of the sample was measured for 60 minutes. Then Potentiodynamic polarization curves was performed to determine the corrosion potential and corrosion current density. The working electrode was polarized at scanning rate of $0.2 \mathrm{mVs}^{-1}$. Electrochemical impedance spectroscopy (EIS) was performed in the frequency range from $50 \mathrm{kHz}$ to $1000 \mathrm{mHz}$. The amplitude of the applied signal was $\pm 10 \mathrm{mV}$ with respect to the open circuit potential. Finally, potentiodynamic cyclic anodic polarization were measured between -0.8 and $+0.2 \mathrm{~V}$ at scanning rate of $10 \mathrm{mVs}^{-1}$. All measurements were carried out at room temperature.

Table 1:-The chemical composition of the samples used, mass \%

\begin{tabular}{|c|c|c|c|c|c|c|c|c|}
\hline Si & Fe & Cu & Mn & Mg & Cr & Zn & Ti & Al \\
\hline 0.06-0.12 & $\mathbf{0 . 2 5 - 0 . 3 5}$ & $\mathbf{0 . 0 5}$ & $\mathbf{0 . 0 2}$ & $\mathbf{0 . 0 2} \mathrm{max}$ & $\mathbf{0 . 0 2} \mathrm{max}$ & $\mathbf{0 . 0 1} \mathrm{max}$ & $\mathbf{0 . 0 1 - 0 . 0 2}$ & Bal. \\
\hline
\end{tabular}

Table 2:-Technological process of rare earth sealing

\begin{tabular}{|c|c|c|c|c|c|}
\hline $\begin{array}{c}\mathrm{Ce}\left(\mathrm{NO}_{3}\right)_{3} \\
\mathrm{~g} / \mathrm{L}\end{array}$ & $\begin{array}{c}\mathbf{H}_{2} \mathbf{O}_{2} \\
\mathbf{g} / \mathbf{L}\end{array}$ & $\begin{array}{c}\mathbf{H}_{3} \mathbf{B O}_{3} \\
\mathbf{g} / \mathbf{L}\end{array}$ & $\mathbf{p H}$ & $\begin{array}{c}\text { Temperature } \\
{ }^{\mathbf{0}} \mathbf{C}\end{array}$ & $\begin{array}{c}\text { Time } \\
\mathbf{h}\end{array}$ \\
\hline 3.0 & $\mathbf{0 . 3}$ & $\mathbf{0 . 5}$ & $\mathbf{5 . 0}$ & $\mathbf{3 0}$ & $\mathbf{2}$ \\
\hline
\end{tabular}

\section{Results and discussion:-}

Analysis of the surface morphology:-

Prior to anodizing, the morphology of the 1050A aluminum alloy surface developed during etching and desmutting was examined using SEM Fig. 1.1.a. The smut layer formed in $\mathrm{NaOH}$ solution was removed during immersion in nitric acid. The surface showed cavities where second phase had been lost either due to dissolution or detachment. Figs. 1.1.b and c show the surface images of the aluminum samples after anodizing. As can be seen, pores are embedded in the middle of hexagonal structures of the AAO layer. Those pores are located perpendicularly and parallel to the barrier layer surface and to each other, respectively [24]. The diameter of the pores was approximately $100 \mathrm{~nm}$. 
Fig. 1.1.d shows the electrophoretic deposition (EPD) of silica nanoparticles on the surface area and in pores at $\mathrm{pH}$ 10. EPD of silica is an easy process because silica suspensions are characterized by spherical particles and high negative zeta potential, providing good stability of the suspension and efficient migration [25]. Moreover, the electric fields at the pore wall of AAO can attract negatively charged particles. It was reported that the pore walls of the anodic alumina are positively charged [26]. On the other hand, particle movement occurred because the average particle size $(\sim 20 \mathrm{~nm})$ was smaller enough than the average pore diameter $(\sim 100 \mathrm{~nm})$ so that particles can be incorporated into pores structures of AAO.

The morphology of the aluminum surface after $\mathrm{SiO}_{2}$ nanoparticles impregnation and sealing impregnated anodic layer in solution containing $\mathrm{Ce}^{3+}$ at room temperature are presented in Fig.1.1.e, where it is difficult to distinguish individual $\mathrm{Ce}^{3+}$ particles since they have merged to form agglomerates that have resulted in the formation of an apparently continuous film over the anodized surface. The thickness of the anodized coating increased about 3 to5 $\mu \mathrm{m}$ after sealing. The increased intensity of the yellow colour of the coating, Fig. 1.2, may indicate an increased thickness of the cerium-rich layer. However, a further reason for the intense yellow colour may be an increased presence of $\mathrm{Ce}^{4+}$ compounds [27].

In order to determine $\mathrm{SiO}_{2}$ nanoparticles and cerium concentrations after the different sealing steps, EDX analysis was employed, Table 3. It is evident that, the surface contents of $\mathrm{SiO}_{2}$ nanoparticles are $31.34 \mathrm{wt} \%$ and $19.74 \mathrm{wt} . \%$ after the first and the second sealing step respectively. While, the surface of impregnated and sealed sample contains about 34.02 wt. \% of cerium. The higher Ce concentration is due to the deposition of a thicker cerium-rich layer as mentioned in SEM, Figs. 1.1.e.

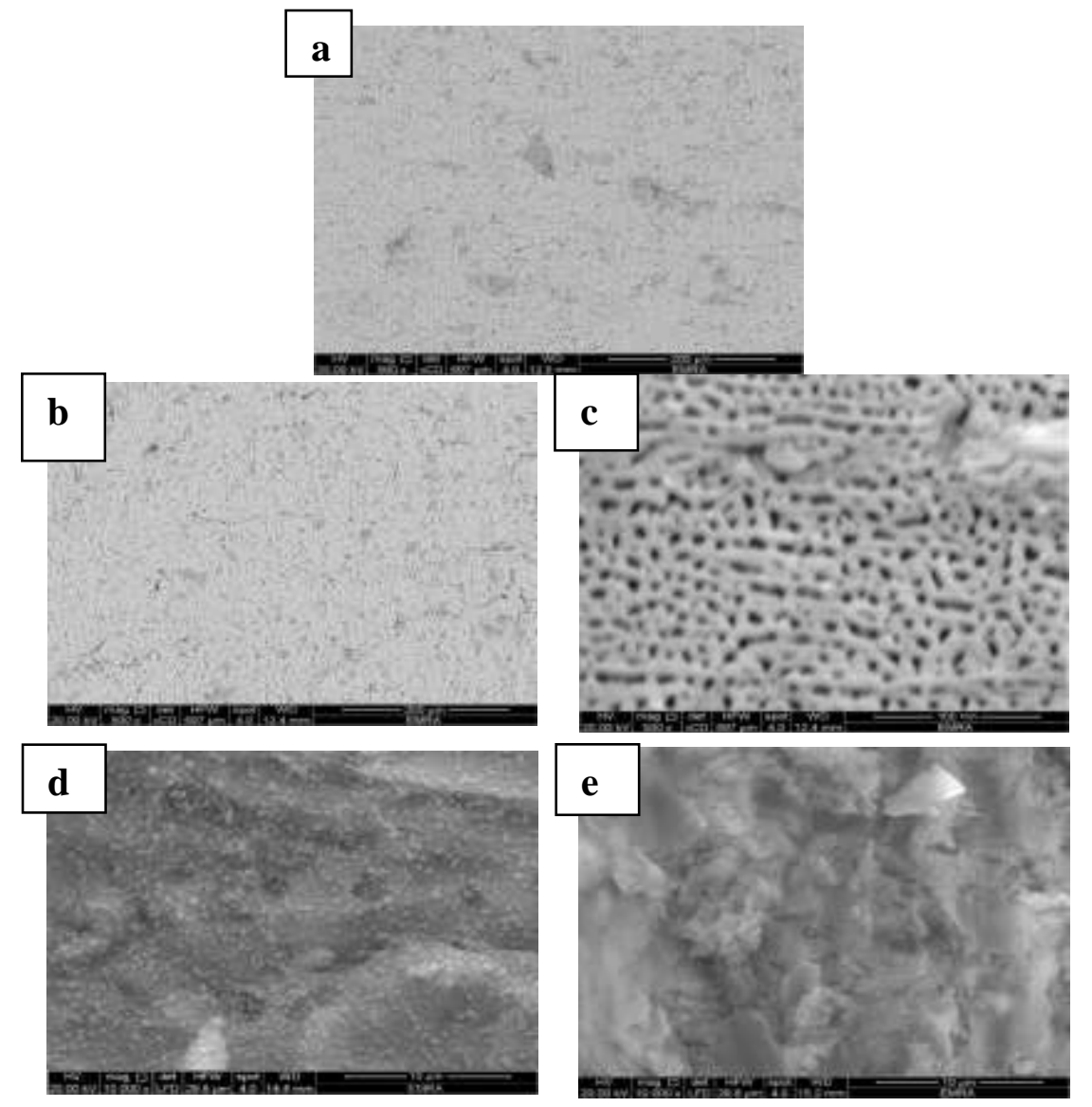

Fig.1.1:- SEM micrographs of the surface of 1050 aluminum alloy after etching (a) after anodizing low magnification (b) and high magnification (c), after first sealing step (d) and after second sealing step (e). 


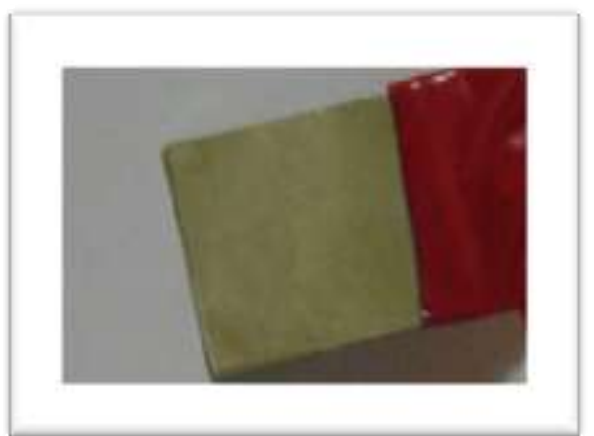

Figure 1.2:- Picture of 1050 aluminum alloy after second sealing step

Table.3:- EDX abundances of elements on the surface formed after first (I) and Second (II) sealing steps.

\begin{tabular}{|c|c|c|c|c|}
\hline Elements, wt.\% & $\mathbf{A l}(\mathbf{K})$ & $\mathbf{O}(\mathbf{K})$ & $\mathbf{S i}(\mathbf{K})$ & $\mathbf{C e}(\mathbf{L})$ \\
\hline I & 45.95 & 22.71 & 31.34 & - \\
\hline II & 0.12 & 46.12 & 19.74 & 34.02 \\
\hline
\end{tabular}

\section{Potentiodynamic polarization measurements:-}

The polarization curves of the tested samples in $3.5 \% \mathrm{NaCl}$ are represented in Fig. 2. As received aluminum shows the highest current densities combined with the lowest cathodic corrosion potential. It is clear that in this case the corrosion rate is highest. Corrosion potentials of AAO with open and impregnated pores are more or less similar to the potential of as received aluminum. Nevertheless, the corrosion current density and also anodic and cathodic currents are much smaller. This is due to the passive oxide layer. AAO with impregnated pores sample has much better anti-corrosive properties compared to AAO sample, where the open pores of the outer layer allow diffusion of aggressive $\mathrm{Cl}^{-}$ions into the structure of the oxide, in which the only hindrance is the barrier type layer [28, 29]. The anodic and cathodic current densities of AAO after impregnation and sealing by Ce conversion coating are much lower compared to as received aluminum, anodized and impregnated samples. Table 5 presents the corrosion potentials and corrosion current densities, calculated by the Tafel method, for the tested samples.

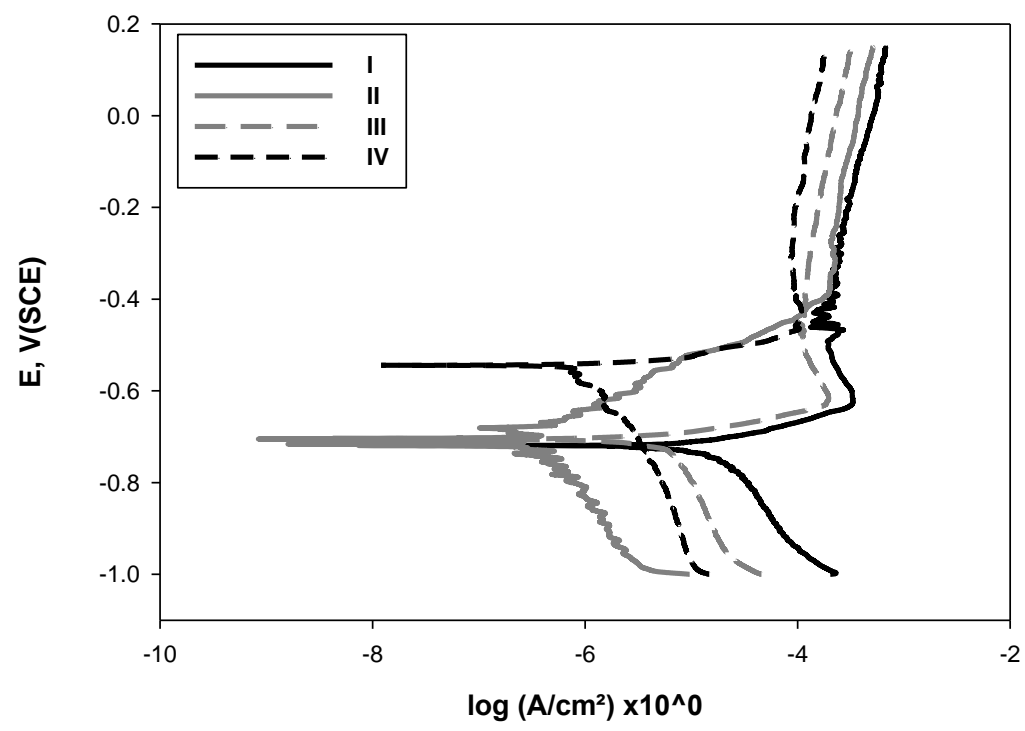

Fig.2:- Polarization curves for as received aluminum (I), AAO (II), after first (III) and Second (IV) sealing steps in $3.5 \mathrm{wt} \% \mathrm{NaCl}$ solution. 
Table 4:- Corrosion potentials and corrosion current densities for as received aluminum (I), AAO (II), after first (III) and Second (IV) sealing steps.

\begin{tabular}{|c|c|c|}
\hline Samples & $\begin{array}{c}\text { Ecorr } \\
\mathbf{m V}\end{array}$ & $\begin{array}{c}\text { Icorr } \\
\boldsymbol{\mu A} / \mathbf{c m}^{\mathbf{2}}\end{array}$ \\
\hline I & -725.7 & 14.34 \\
\hline II & -719.7 & 11.92 \\
\hline III & -705.9 & 9.27 \\
\hline IV & -545.1 & 0.87 \\
\hline
\end{tabular}

\section{Electrochemical Impedance Spectroscopy (EIS):-}

Nyquist and Bode phase plots of the tested samples in 3.5\% NaCl are shown in Fig.3. There are two time constants in the spectra obtained on the test from the Fig.3.a and b, as seen from the Bode diagram, correspond to the two capacitors arc in Fig.3.c, as seen from the Nyquist diagram. The first constant appearing at high frequency represents electric double layer capacitor and the mass transfer resistance between the solution and Al sample. The second one appearing at low frequency represents the capacitance and resistance of anodized coating under corrosion reaction. The model of the sealing anodized 1050A aluminum alloy was proposed elsewhere is shown as Fig.3.d, The anodized coating can be divided into two parts. The layer on the matrix of the aluminum alloy is the barrier layer. The layer with the porous structure on the barrier layer is the porous layer. By using EPD technique, $\mathrm{SiO}_{2}$ nanoparicales filling the pores of the anodized coating at the first sealing step. At the same time, $\mathrm{SiO}_{2}$ nanoparicales deposits formed on the surface of the anodized coating create a barrier to the permeation of Ce solution getting into the pores, during second sealing step. When the pore-structured of the anodizing film is completely covered, the Ce conversion coating will form on the surface of the anodizing coating [30]. Therefore, the obtained spectra are modeled using the equivalent circuit shown in Fig. 3.e, where Rs represents solution resistance, Rct charge transfer resistance, $\mathrm{C}_{\mathrm{dl}}$ double-layer capacitance, and $\mathrm{Rp}$ and $\mathrm{Cc}$ parameters attributed to the anodized coating layer.

The first arc in the Nyquist plot, Fig3.c, reflects the information of the outer Ce conversion coating layer. The second arc in Nyquist plot reflects the information of the inner impregnated anodized coating layer. It can be seen from Fig.3.c; the diameter of the second arc is much larger than that of the first arc for sample undergo the two sealing steps. This indicates that the polarization resistance $\mathrm{Rp}$ of the inner impregnated anodized coating layer is much higher than that of the outer layer Ce conversion coating which meaning completely impregnation of the pours after second sealing step. Thus the inner anodized coating takes the leading role for the corrosion protection of aluminum alloy matrix.

The Rp value, Table 5, for anodized sample undergo the two sealing steps is $14.24 \mathrm{Kohm} . \mathrm{cm}^{2}$, which is about 3 times than anodizing sample impregnating with $\mathrm{SiO}_{2}$ nanoparticles only, about 8 times than anodized sample and about 20 times than received aluminum.

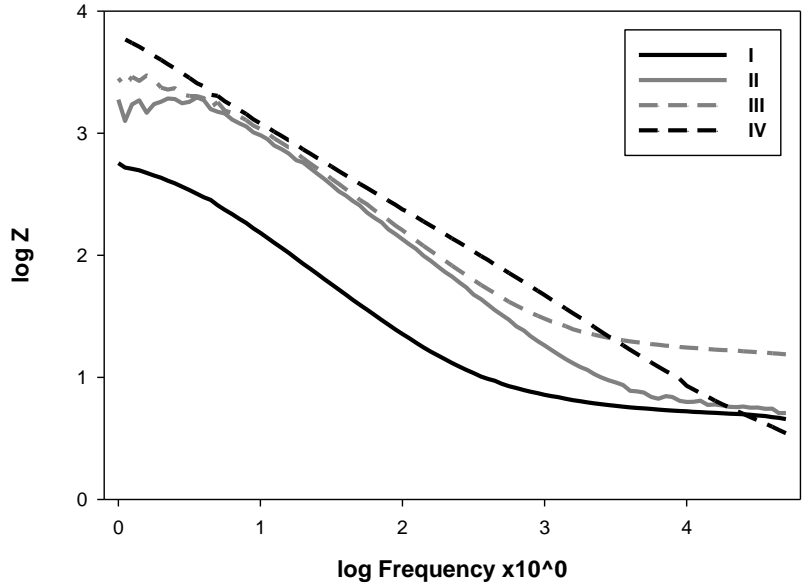

a 


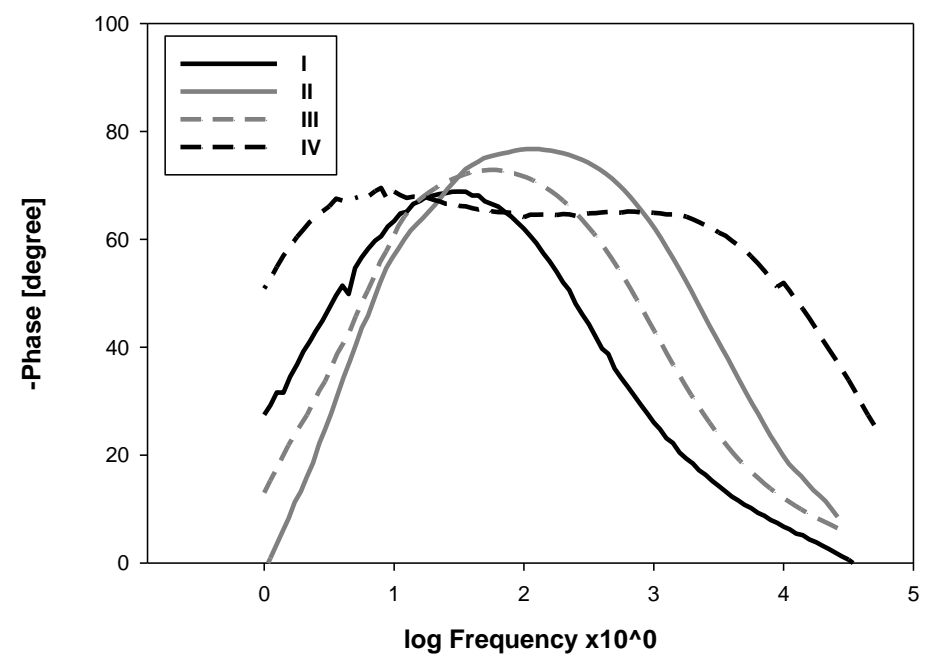

b

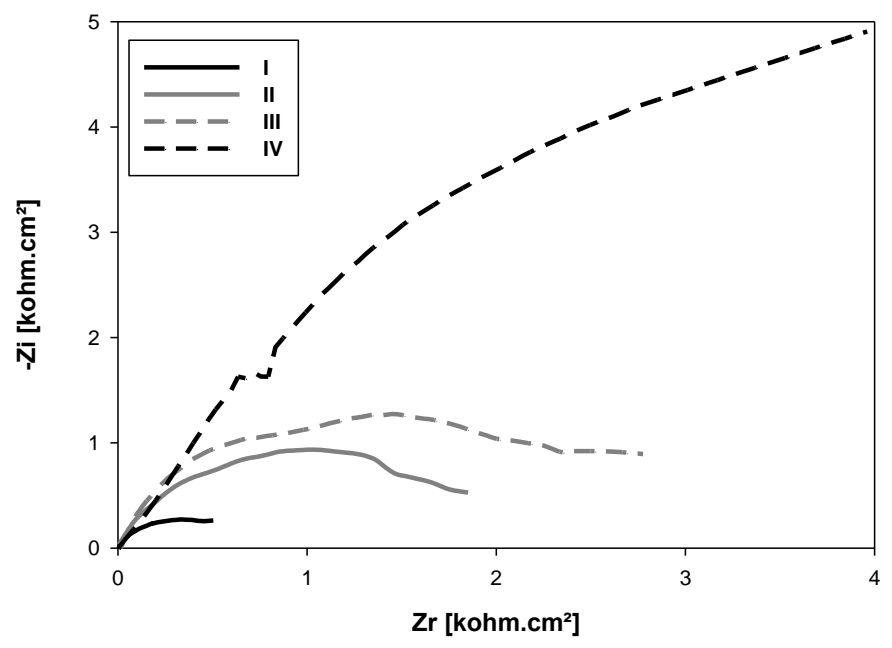

C
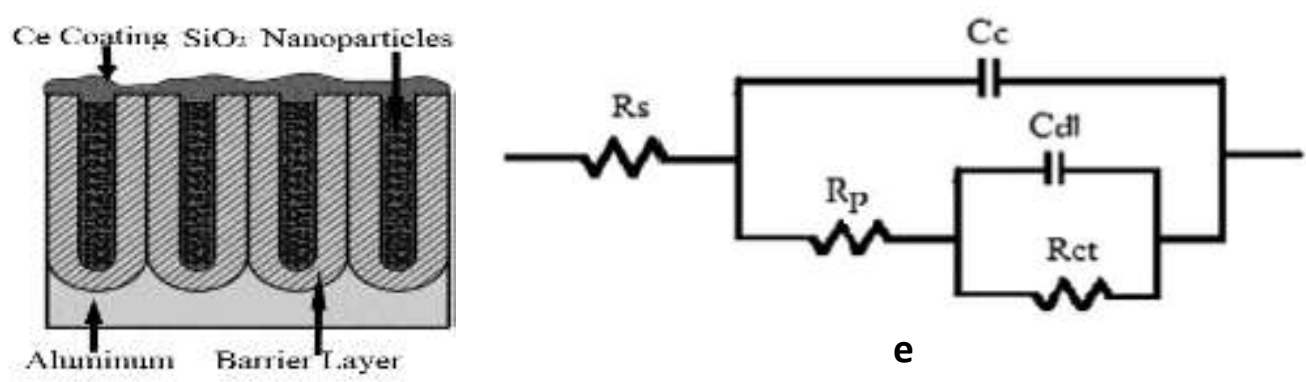

e

d

Fig.3:-Bode (a) and Nyquist (b) plots of as received aluminum (I), AAO (II), after first (III) and Second (IV) sealing steps in $3.5 \mathrm{wt} \% \mathrm{NaCl}$ solutions. with Scheme of impregnated AAO \& Ce conversion coating (c) and electrochemical equivalent circuits used for fitting the experimental data (d). 
Table 5:- Electrochemical parameters fitted from EIS measurement for as received aluminum (I), AAO (II), after first (III) and Second (IV) sealing steps.

\begin{tabular}{|c|c|c|}
\hline Samples & $\mathbf{R}_{\mathbf{p}} \mathbf{k o h m . \mathbf { c m } ^ { 2 }}$ & $\mathbf{C}_{\mathbf{d l}} \boldsymbol{\mu F} / \mathbf{c m}^{\mathbf{2}}$ \\
\hline I & 0.6993 & 127.4 \\
\hline II & 1.792 & 14.03 \\
\hline III & 2.953 & 13.47 \\
\hline IV & 14.24 & 1.117 \\
\hline
\end{tabular}

\section{Potentiodynamic cyclic anodic polarization measurements:-}

In order to evaluate further the corrosion resistance of anodizing coatings in corrosive $3.5 \% \mathrm{NaCl}$ solution, potentiodynamic cyclic anodic polarization measurements were performed. Fig. 4 revealed that, for the tested samples, the potential of the AAO after impregnation and sealing by Ce conversion coating, after second sealing step, was approximately 181,175 and $161, \mathrm{mV}$ positive than as received aluminum, AAO with open and impregnated pores sample respectively. Accordingly, the highest pitting resistance can be obtained from the sample after second sealing step. Also, sample after second sealing step, showed better performance where the hysteresis loop observed during the reverse anodic scan, which indicates the possibility of pitting corrosion, was completely diminished. Moreover, a little shift towards more passive exchange current was noticed for that sample compared to the rest sample.

This finding was in consistence with EIS and potentiodynamic polarization measurements.

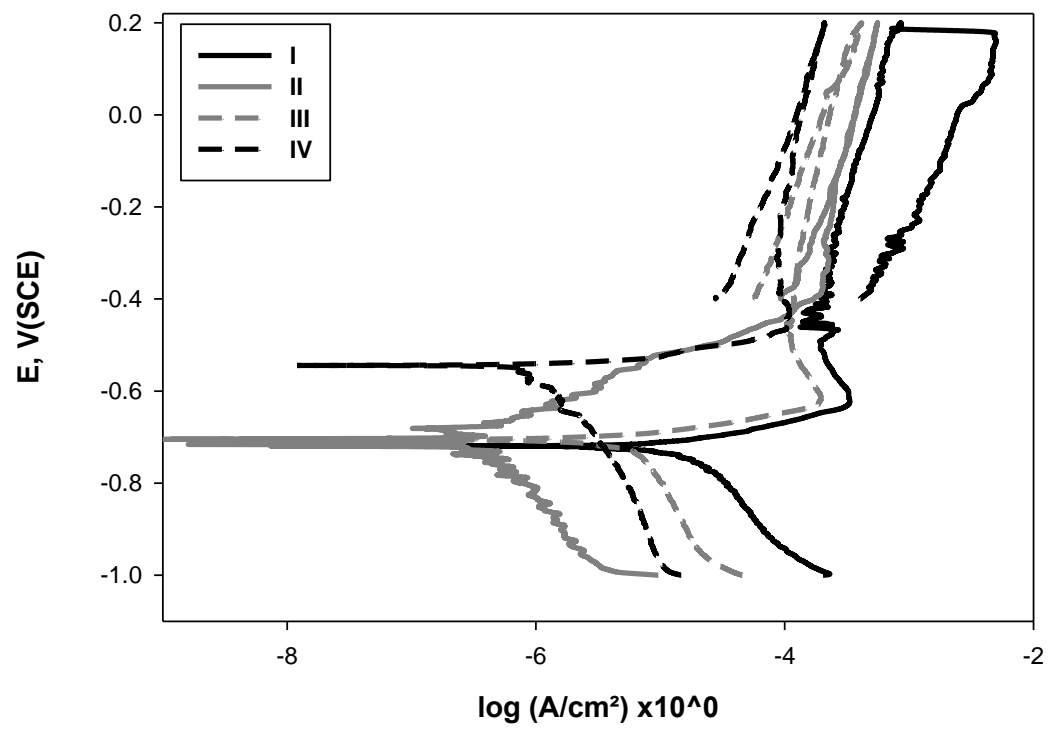

Fig.4:- Potentiodynamic cyclic anodic polarization curves for as received aluminum (I), AAO (II), after first (III) and Second (IV) sealing steps in $3.5 \mathrm{wt} \% \mathrm{NaCl}$ solution.

\section{Conclusion:-}

The electrochemical characteristics of aluminum due to the deposition of $\mathrm{SiO}_{2}$ nanoparticles by electrophoretic deposition inside a porous anodic aluminum oxide film followed by sealing using cerium conversion coating technique were studied in the present work, leading to the following experimental evidences:

1. The surface morphology after first sealing step showed deposition of $\mathrm{SiO}_{2}$ nanoparticles in AAO pores and on its surface. While, after second sealing step a continuous film of agglomerated $\mathrm{Ce}^{3+}$ particles were formed over the anodized surface.

2. The results of electrochemical impedance spectroscopy, potentiodynamic polarization and potentiodynamic cyclic anodic polarization measurements which employed to evaluate the corrosion resistance of resulting anodized coating in $3.5 \mathrm{wt} . \% \mathrm{NaCl}$ solution showed significantly corrosion resistance character. 


\section{References:-}

1. R. M. Abou Shahba, A. S. Ibrahim, W. A. Hussein, N. K. Shehata, and W. A. Ghanem, Researcher, 3(2011)14.

2. W. A. Hussein, A. S. I. Ahmed, W. Ghanem and G. A. Gaber, International Journal of Metallurgical, Materials and Chemical Engineering, 1(2016) 41.

3. M. J. Hurtado, Electrochimica Acta, 25(1) (2007)153.

4. M .Hideki, H .Fumio and O .Sachiko, Journal of the Electrochemical Society, 144(5) (1997) 127.

5. G. E. Thompson and G. C. Wood, Nature 290(1981) 230.

6. V. Bello and M. Yukimori, Method for anodizing aluminum (1990) (United Estates: Patent US 4894127 A).

7. A .Camargo, W. Aperador, A .Rios, C. Ortiz and E. Vera, Revista Colombiana de Física 41(2)(2009) 261.

8. A .Dattilo, S Tamiro and C. Romano Anodizing process, with low environmental impact, for a woodpiece of aluminum or aluminum alloys (2002) (United States: Patent US 20020157961 A1).

9. J. M. Montero, M. Sarret and C. Müller, Surface and Coatings Technology 201(14) (2007) 6352.

10. K. Shimizu, K. Kobayas, G. E. Thompson and G. C. Wood, Philosophical Magazine, 66 (7) (1992) 643.

11. Z. Yu, Z. Penghui and Z. Jingmao, Surface \& Coatings Technology, 166 (2003) 237.

12. S. Guangling, Surface \& Coatings Technology, 203 (2009) 3618.

13. V. López, E. Otero, A. Bautista and J.A. González, Surface \& Coatings Technology, 124 (2000) 76.

14. N.P. Hu, X.C. Dong, X.Y. He, J. F. Browning and D. W. Schaefer, Corrosion Science, 97 (2015) 17.

15. M.J. Bartolomé, V. López, E. Escudero, G. Caruana and J.A. González, Surface \& Coatings Technology, 200 (2006) 4530.

16. M. Shahzad, M. Chaussumier, R. Chieragatti, C. Mabru and F. Rezai Aria, Surface \& Coatings Technology, 206 (2012) 2733.

17. M. Mohedano, E. Matykina, R. Arrabal, B. Mingo and A. Pardo, Applied Surface Science, 346 (2015) 57.

18. B. Rachel Cheng and Ling Hao, Transactions of the Institute of Metal Finishing, 98 (5) (2000) 48.

19. I. Seo, C.W. Kwon, H.H. Lee, Y.S. Kim, K.B. Kim and T.S. Yoon, Electrochemical and Solid-State Letters 12 (2009) K59.

20. L. Bazin, M. Gressier, P.L. Taberna, M.J. Menu and P. Simon, Chemical Communications. (2008) 5004-5006.

21. K. Grandfield and I. Zhitomirsky, Materials Characterization. 59 (2008) 61-67.

22. M.N. Naim, M. Iijima, K. Sasaki, M. Kuwata, H. Kamiya and I.W. Lenggoro, Powder Technology. 21 (2010) 534.

23. S. Ono and N. Masuko, Surface \& Coatings Technology, 169-170 (2003) 139.

24. L. Bazin, M. Gressier, P.L. Taberna, M.J. Menu and P. Simon, Chemical Communications. (2008) 5004.

25. G. Cao and D. Liu, Adv. colloid and interface science. 136 (2008) 45.

26. A. Nourmohammadi, M. Bahrevar and M. Hietschold, The Journal of Alloys and Compounds. 473 (2009) 467.

27. P. Burroughs, A. Hamnett, A.F. Orchard and G. Thornton, Journal of the Chemical Society, Dalton Transactions, 17 (1976), 1683.

28. J. Hitzig, K. Juettner and W.J. Lorenz, Journal of the Electrochemical Society, 133 (1986) 887.

29. E. McCafferty, Corrosion Science, 37 (1995) 481.

30. X.Yu, C.Cao and Z.Yao: Journal of Materials Science Letters, 19 (2000)1907. 